\title{
Educação sexual na percepção de pais e adolescentes: uma revisão sistemática
}

\author{
Sex education in the perception of parents and \\ adolescents: a systematic review
}

\section{La educación sexual en la percepción de padres y adolescentes: una revisión sistemática}

\section{Pâmela Schultz Danzmann' ${ }^{1}$ (i) Liliane Tomazi Vestena ${ }^{2}$ (1) Ana Claudia Pinto da Silva ${ }^{3}$ (1) Maristela Jaqueline Reis Peixoto 4 (1)}

${ }^{1}$ Autora para correspondência. Universidade Franciscana (Santa Maria). Rio Grande do Sul, Brasil. pamelapsicologia10@gmail.com 2,4Universidade Franciscana (Santa Maria). Rio Grande do Sul, Brasil. lilianetomazi@gmail.com, maris.rpeixoto@gmail.com ${ }^{3}$ Universidade Federal de Santa Maria (Santa Maria). Rio Grande do Sul, Brasil. anaclaudiaps14@hotmail.com

\begin{abstract}
RESUMO | INTRODUÇÃO: A adolescência é um período marcado por mudanças biopsicossociais nas quais as relações com os pares ganham muita importância e a sexualidade apresenta-se de forma evidente. OBJETIVO: Compreender por meio da revisão de produção científica como são transmitidas as informações sobre educação sexual para os adolescentes em diferentes contextos, conforme a percepção dos cuidadores parentais e dos próprios adolescentes. MÉTODO: Trata-se de uma revisão sistemática da literatura, na qual a busca dos artigos foi realizada nas bases de dados, Lilacs, Scielo, Directory of Open Access Journals, e Biblioteca Virtual da Saúde, entre os anos de 2016 e 2020 . Foram verificados por meio da revisão nos relatos dos pais e adolescentes o que entendem sobre educação sexual. CONCLUSÃo: Compreendeu-se que os adolescentes buscam por essas informações principalmente com os membros da família, mesmo que algumas orientações sejam transmitidas com pouca clareza, em segundo apareceu o cenário escolar, na sequência os meios tecnológicos, os amigos e os profissionais da saúde.
\end{abstract}

PALAVRAS-CHAVE: Educação. Sexualidade. Adolescente.

ABSTRACT | INTRODUCTION: Adolescence is a period marked by biopsychosocial changes, in which relationships with peers gain great importance and sexuality is evident. OBJECTIVE: To understand, through the review of scientific production, how information on sex education is transmitted to adolescents in different contexts, according to the perception of parental caregivers and the adolescents themselves. METHOD: This is a systematic review of the literature, in which the search for articles was performed in the databases Lilacs, Scielo, Directory of Open Access Journals, and Biblioteca Virtual da Saúde, between 2016 and 2020. verified by reviewing the reports of parents and adolescents what they understand about sex education. CONCLUSION: It was understood that adolescents seek this information mainly with family members, even if some guidelines are transmitted with little clarity, secondly the school scenario appeared, followed by technological means, friends, and health professionals.

KEYWORDS: Education. Sexuality. Adolescent.

RESUMEN | INTRODUCCIÓN: La adolescencia es un período marcado por cambios biopsicosociales, en el que las relaciones con los pares cobran gran importancia y la sexualidad es evidente. OBJETIVO: Comprender, a través de la revisión de la producción científica, cómo se transmite la información sobre educación sexual a los adolescentes en diferentes contextos, según la percepción de los padres cuidadores y de los propios adolescentes. MÉTODO: Se trata de una revisión sistemática de la literatura, en la que se realizó la búsqueda de artículos en las bases de datos Lilacs, Scielo, Directory of Open Access Journals y Biblioteca Virtual da Saúde, entre 2016 y 2020. verificado mediante la revisión de los relatos de los padres y adolescentes lo que entienden sobre educación sexual. CONCLUSIÓN: Se entendió que los adolescentes buscan esa información principalmente con los familiares, aunque algunas orientaciones se transmiten con poca claridad, en segundo lugar, apareció el escenario escolar, seguido de medios tecnológicos, amigos y profesionales de la salud.

PALABRAS CLAVE: Educación. Sexualidad. Adolescente. 


\section{Introdução}

A adolescência é um período importante no desenvolvimento humano, caracterizada por uma série de transformações físicas, emocionais e sociais. Conforme a Organização Mundial de Saúde (2009), a adolescência compreende-se como uma das fases do desenvolvimento que corresponde entre os 10 a 19 anos de idade (OMS, 2009). No que se refere ao Estatuto da Criança e do Adolescente (ECA), a adolescência situa-se entre os 12 e os 18 anos incompletos (Ministério da Educação, 1990). Desse modo, pode ser compreendida como um período de transição entre a infância e a vida adulta (Papalia \& Feldman, 2013).

É importante salientar que não existe um consenso sobre quando se inicia e quando se encerra a adolescência, e que legislações e organizações como descritas acima seguem marcadores cronológicos de idades para defini-la. Por outro lado, há estudos que consideram o contexto social, econômico, político e cultural que o indivíduo está inserido para definir o que é adolescência, sendo assim na atualidade não se enfatiza a adolescência como única, mas sim várias "adolescências" (Arpini \& Witt, 2015; Bock, 2015).

Este período é marcado por mudanças biopsicossociais, nas quais as relações com os pares ganham importância e a sexualidade apresenta-se de forma clara (Freire et al., 2017). Porém, as manifestações sexuais podem se dar de diferentes formas para cada indivíduo, pois são influenciadas pelas crenças, valores familiares e pessoais, tabus e normas morais construídas socialmente (Arpini \& Witt, 2015).

Neste sentido, uma rede familiar faz-se necessária durante a adolescência, na qual os pais e/ou cuidadores possam enfatizar e orientar os filhos sobre educação sexual e reprodutiva, bem como sanar as dúvidas diante dos enfrentamentos ocasionados por este período. Para tanto, é importante que o adolescente tenha acesso a esclarecimentos sobre questões relacionadas ao sexo (ato sexual) e ao próprio desenvolvimento da sexualidade (transformações fisiológicas, cognitivas, emocionais e comportamentais), livres de preconceitos, preparando assim o adolescente para uma vida sexual segura e de cuidados com o seu próprio corpo (exposição, contaminação por doenças e gravidez indesejada) (Genz et al., 2017).
Sendo assim, sabe-se que muitos pais enfrentam dificuldades em abordar a temática da educação sexual com seus filhos, e muitas famílias consideram o assunto como um tabu. Nesses casos, os adolescentes podem não possuir abertura para falar sobre suas dúvidas, anseios e necessidades frente ao desenvolvimento de sua sexualidade (Furlanetto et al., 2018). Diante da identificação e compreensão dos amigos, os adolescentes recorrem aos seus pares, na busca por informações seguras. Muitas vezes, os amigos acabam por se tornar a principal via de intimidade na adolescência, servindo como modelos e influenciando em atos e comportamentos (Seloilwe et al., 2015). Assim, alguns grupos de amigos podem favorecer condutas de risco e aumentar a probabilidade de adolescente praticar ações não saudáveis, tornando cada vez mais importante a supervisão e orientação dos pais (Savegnago \& Arpini, 2016).

Considerando que os questionamentos são comuns ao período do desenvolvimento, muitas vezes a busca por informações a respeito da sexualidade culmina nos meios tecnológicos. Porém, sabe-se que as fontes de informações mediadas por meios digitais nem sempre proporcionarão esclarecimentos de forma segura e adequada. O acesso ao conteúdo da internet sem o monitoramento da rede de cuidados dos adolescentes, pode fazer com que esses encontrem informações distorcidas sobre sexo e sexualidade (Furlanetto et al., 2019). Esse fato pode favorecer a exposição de riscos emocionais e sexuais, tal como a disseminação de informações íntimas nas redes sociais. Sendo assim, a repercussão desses episódios pode culminar em efeitos psicológicos extremamente danosos aos adolescentes (Seloilwe et al., 2015).

Alguns adolescentes recorrem também aos professores e profissionais que atuam na escola, assim como aos profissionais da saúde para sanar suas dúvidas (Gava \& Villela, 2016). Desta forma, salienta-se a importância de que a educação sexual seja pautada no diálogo e na escuta profissional dos adolescentes, pois o que está colocado é uma educação preventiva, na qual se contempla os diferentes modos de viver a sexualidade e "as adolescências" (Furlanetto et al., 2018).

Sendo assim, o trabalho justifica-se pela importância de discutir a temática sobre educação sexual e a compreensão dos aspectos que envolvem a sexualidade 
no período da adolescência, visto que não existem muitos estudos que versam sobre esse tema na adolescência. Assim, tanto os pais quanto os adolescentes podem acabar acessando informações com pouca ou nenhuma cientificidade na internet.

O estudo se torna relevante por existirem poucos estudos brasileiros que abordam de uma forma clara e reflexiva o tema. Além disso, os estudos publicados trazem a percepção parental ou dos filhos sobre educação sexual, poucos discutem os dois pontos de vista, o que é fundamental para compreender as principais dúvidas, medos e desconfortos de ambos os lados. Objetiva-se compreender por meio da revisão de produção científica como são transmitidas as informações sobre educação sexual para os adolescentes em diferentes contextos, conforme a percepção dos cuidadores parentais e dos próprios adolescentes.

\section{Método}

O estudo caracteriza-se como uma revisão sistemática da literatura que permite uma busca rigorosa e seletiva de estudos publicados em um determinado período (Galvão \& Pereira, 2014). Essa revisão busca responder à seguinte pergunta norteadora: Como são transmitidas as informações sobre educação sexual para os adolescentes no contexto familiar, escolar, da saúde, rede de amigos e tecnológico na visão dos pais e filhos? A pergunta norteadora foi elaborada por meio da estratégia PICO (paciente, interesse ou intervenção, comparação ou contexto e resultados), em que: $P$ = adolescentes e pais; $I$ = Educação sexual; $C$ = família, escola, tecnologia, amigos e profissionais da saúde; $\mathrm{O}$ = entender como a educação sexual é transmitida para os adolescentes.

O levantamento bibliográfico ocorreu no primeiro bimestre do ano de 2021 por meio das bases Lilacs, Scielo, Directory of Open Access Journals (DOAJ), e Biblioteca Virtual da Saúde (BVS) através dos descritores booleanos "Educação Sexual OR Sexualidade AND Adolescentes OR Adolescência AND Família OR Pais". Os artigos identificados durante a busca nas bases de dados foram selecionados a partir da leitura dos títulos, seguido dos resumos por duas pesquisadoras independentes (A e B), sendo os desacordos resolvidos por consenso. Após esta etapa, uma nova avaliação foi realizada e os estudos foram analisados na íntegra.
Foram encontrados documentos nas línguas portuguesa, inglesa e espanhola, apesar da utilização de descritores em português. O recorte temporal adotado refere-se aos últimos cinco anos desde o início da pesquisa, o que inclui os anos de 2016 a 2020. Os critérios para a seleção do material foram artigos que expusessem sobre a temática educação sexual na adolescência, bem como por serem conteúdos gratuitos. Os idiomas selecionados foram o português, inglês e o espanhol. Os critérios de exclusão do material foram documentos em livros, e-books, artigos de revisão (bibliográfica, integrativa, sistemática e outros), resumos, dissertações, dentre outros materiais, que estivessem fora do recorte temporal estabelecido, descrevessem apenas infecções sexualmente transmissíveis, e não trouxessem a percepção familiar ou do adolescente acerca da educação sexual.

As pesquisadoras selecionaram previamente cinco categorias: contexto familiar, contexto escolar, contexto tecnológico, contexto da saúde e amigos. Durante a seleção e leitura dos materiais esperava-se confirmar estas categorias mediante análise de conteúdo, seguindo-se os três passos propostos por (Bardin, 2016). Na primeira etapa (a) pró-análise, foi realizada a leitura flutuante dos materiais. $\mathrm{Na}$ segunda etapa, (b) para a exploração do material foram escolhidos conteúdos dos artigos e agrupados em uma única categoria (Educação sexual em diferentes contextos), devido a quantidade de resultados encontrados. E na última etapa (c) análise e interpretação dos dados, a categoria foi analisada e interpretada com base em estudos prévios sobre o tema publicados na literatura nacional e internacional (Bardin, 2016).

Por fim, tentou-se minimizar o risco de viés com uma metodologia criteriosa e minuciosa, onde se utilizou base de dados e descritores específicos, exclusão dos artigos e demais materiais que não condizem com a pergunta norteadora. Tudo isso ligado ao modelo PRISMA, recomendado para o desenvolvimento de revisões sistemáticas, bibliográficas e meta-análise. Posto isso, o PRISMA baseia-se em um conjunto de itens (checklist), que possui a finalidade de auxiliar os(as) autores(as) a construírem uma lista com o que não pode faltar em cada etapa da revisão sistemática, desde o título, resumo e introdução, orientando-se pelos objetivos, com os principais pontos dos métodos e resultados, encerrando com a discussão e considerações finais (Galvão et al., 2015). 


\section{Resultados}

Foram encontrados e analisados 284 documentos. Destes foram lidos na íntegra 41 artigos e selecionados 14 para a construção desse documento.

Tabela 1. Síntese dos principais artigos apresentados na revisão sistemática (continua)

\begin{tabular}{|c|c|c|c|c|}
\hline $\begin{array}{l}\text { Autores/Ano } \\
\text { bases de } \\
\text { dados }\end{array}$ & $\begin{array}{c}\text { Título } \\
\text { da publicação }\end{array}$ & Participantes & Objetivos & Resultados \\
\hline $\begin{array}{l}\text { 1. Rolim et al., } \\
\text { (2016) } \\
\text { LILACS }\end{array}$ & $\begin{array}{l}\text { Conhecimento e } \\
\text { acesso aos } \\
\text { programas de } \\
\text { educação sexual } \\
\text { e prevenção da } \\
\text { Aids: um estudo } \\
\text { com adolescentes } \\
\text { escolares }\end{array}$ & $\begin{array}{l}1190 \text { adolescentes entre } \\
12 \text { e } 19 \text { anos. }\end{array}$ & $\begin{array}{l}\text { Analisar o } \\
\text { conhecimento e o } \\
\text { acesso aos } \\
\text { programas de } \\
\text { educação } \\
\text { sexual e prevenção } \\
\text { da Aids de } \\
\text { adolescentes } \\
\text { matriculados em } \\
\text { escolas públicas da } \\
\text { região } \\
\text { metropolitana de } \\
\text { Porto Alegre/RS. }\end{array}$ & $\begin{array}{l}\text { A grande maioria dos } \\
\text { adolescentes não tem } \\
\text { conhecimento de } \\
\text { programas/oficinas de } \\
\text { educação } \\
\text { sexual e prevenção da } \\
\text { Aids na escola e no } \\
\text { município. }\end{array}$ \\
\hline $\begin{array}{l}\text { 2. Savegnago } \\
\text { \& Arpini } \\
\text { (2016) } \\
\text { BVS }\end{array}$ & $\begin{array}{l}\text { A Abordagem do } \\
\text { Tema Sexualidade } \\
\text { no Contexto } \\
\text { Familiar: o Ponto } \\
\text { de } \\
\text { Vista de Mães de } \\
\text { Adolescentes }\end{array}$ & $\begin{array}{l}17 \text { mães de adolescentes, } \\
\text { pertencentes a } \\
\text { grupos populares de } \\
\text { uma cidade do interior } \\
\text { do Rio Grande } \\
\text { do Sul. }\end{array}$ & $\begin{array}{l}\text { Apresentar } \\
\text { alguns aspectos } \\
\text { referentes ao } \\
\text { diálogo sobre } \\
\text { sexualidade } \\
\text { entre pais e } \\
\text { adolescentes, a } \\
\text { partir do ponto de } \\
\text { vista de } \\
\text { mulheres que } \\
\text { possuem filhos } \\
\text { adolescentes. }\end{array}$ & $\begin{array}{l}\text { As participantes } \\
\text { apresentaram tanto a } \\
\text { percepção de que os } \\
\text { adolescentes já teriam } \\
\text { informações suficientes } \\
\text { sobre o assunto. }\end{array}$ \\
\hline $\begin{array}{l}\text { 3.Sevilla et al., } \\
(2016) \\
\text { SCIELO }\end{array}$ & $\begin{array}{l}\text { Consistências e } \\
\text { discrepâncias na } \\
\text { comunicação entre } \\
\text { pais e filhos } \\
\text { Crianças sobre } \\
\text { sexualidade. }\end{array}$ & $\begin{array}{l}711 \text { pais/ } \\
\text { mães e } 566 \text { estudantes } \\
\text { masculinos/femininos. }\end{array}$ & $\begin{array}{l}\text { Caracterizar e } \\
\text { compreender os } \\
\text { processos por } \\
\text { que os pais e os } \\
\text { seus filhos } \\
\text { adolescentes se } \\
\text { comunicam sobre a } \\
\text { sexualidade. }\end{array}$ & $\begin{array}{l}\text { A maior discrepância } \\
\text { entre pais e } \\
\text { adolescentes foi a crença } \\
\text { dos adultos de que é } \\
\text { suficiente mencionar } \\
\text { certos tópicos de uma } \\
\text { forma diretiva e as } \\
\text { expectativas das crianças } \\
\text { de que os pais irão } \\
\text { discutir o valor e a } \\
\text { dinâmica da experiência } \\
\text { sexual. }\end{array}$ \\
\hline $\begin{array}{l}\text { 4. Almeida et } \\
\text { al., (2017) } \\
\text { BVS }\end{array}$ & $\begin{array}{l}\text { Conhecimento de } \\
\text { adolescentes } \\
\text { relacionados às } \\
\text { doenças } \\
\text { sexualmente } \\
\text { transmissíveis e } \\
\text { gravidez. }\end{array}$ & $\begin{array}{l}22 \text { adolescentes entre } 16 \\
\text { e } 19 \text { anos } \\
\text { de idade, estudantes do } \\
\text { Ensino Médio em uma } \\
\text { escola pública. }\end{array}$ & $\begin{array}{l}\text { Investigar o } \\
\text { conhecimento de } \\
\text { adolescentes } \\
\text { relacionado às } \\
\text { Infecções } \\
\text { Sexualmente } \\
\text { Transmissíveis (IST), } \\
\text { AIDS e gravidez, } \\
\text { além de conhecer a } \\
\text { compreensão sobre } \\
\text { o papel da escola na } \\
\text { educação sexual. }\end{array}$ & $\begin{array}{l}\text { Os resultados da análise } \\
\text { emergiram quatro } \\
\text { categorias temáticas: } \\
\text { Sexualidade e educação } \\
\text { sexual; Compreensão de } \\
\text { comportamentos de } \\
\text { risco; } \\
\text { Conhecimento de } \\
\text { IST/AIDS; Conhecimento } \\
\text { e práticas de prevenção. }\end{array}$ \\
\hline $\begin{array}{l}\text { 5.Bezerra et } \\
\text { al., (2016) } \\
\text { LILACS }\end{array}$ & $\begin{array}{l}\text { Percepção dos } \\
\text { adolescentes } \\
\text { sobre a atividade } \\
\text { da vida "expressa } \\
\text { sexualidade". }\end{array}$ & 25 adolescentes. & $\begin{array}{l}\text { Analisar a percepção } \\
\text { dos adolescentes } \\
\text { sobre a atividade da } \\
\text { vida "sexualidade } \\
\text { expressa". }\end{array}$ & $\begin{array}{l}\text { Observou-se } \\
\text { vulnerabilidade dos } \\
\text { adolescentes para } \\
\text { gravidez precoce e DST. } \\
\text { Verificou-se que, apesar } \\
\text { de possuírem } \\
\text { conhecimento prévio } \\
\text { sobre práticas sexuais } \\
\text { seguras, expõem-se a } \\
\text { situações de risco. }\end{array}$ \\
\hline
\end{tabular}


Tabela 1. Síntese dos principais artigos apresentados na revisão sistemática (continuação)

\begin{tabular}{|c|c|c|c|c|}
\hline $\begin{array}{c}\text { Autores/Ano } \\
\text { bases de } \\
\text { dados }\end{array}$ & $\begin{array}{c}\text { Título } \\
\text { da publicação }\end{array}$ & Participantes & Objetivos & Resultados \\
\hline $\begin{array}{l}\text { 6.Freire et al., } \\
(2017) \\
\text { DOAJ }\end{array}$ & $\begin{array}{l}\text { Aspectos } \\
\text { psicossociais da } \\
\text { sexualidade na } \\
\text { adolescência: } \\
\text { diálogos e } \\
\text { aprendizagem na } \\
\text { escola. }\end{array}$ & $\begin{array}{l}20 \text { estudantes } \\
\text { Ensino Fundamental II e } \\
\text { Médio. }\end{array}$ & $\begin{array}{l}\text { Compreender os } \\
\text { aspectos } \\
\text { psicossociais da } \\
\text { sexualidade de } \\
\text { adolescentes, } \\
\text { revelados através do } \\
\text { desenvolvimento de } \\
\text { oficinas. }\end{array}$ & $\begin{array}{l}\text { Muitos adolescentes têm } \\
\text { receio de conversar com } \\
\text { a família por } \\
\text { acreditarem que } \\
\text { serão repreendidos e } \\
\text { têm pouco } \\
\text { conhecimento sobre } \\
\text { educação sexual. }\end{array}$ \\
\hline $\begin{array}{l}\text { 7.Genz et al., } \\
(2017) \\
\text { DOAJ }\end{array}$ & $\begin{array}{l}\text { Doenças } \\
\text { sexualmente } \\
\text { transmissíveis: } \\
\text { Conhecimento e } \\
\text { comportamento } \\
\text { sexual dos } \\
\text { adolescentes. }\end{array}$ & $\begin{array}{l}945 \text { alunos que estavam } \\
\text { frequentando a escola no } \\
\text { momento da pesquisa. }\end{array}$ & $\begin{array}{l}\text { Avaliar o } \\
\text { conhecimento e } \\
\text { comportamento } \\
\text { sexual de } \\
\text { adolescentes sobre } \\
\text { doenças } \\
\text { sexualmente } \\
\text { transmissíveis. }\end{array}$ & $\begin{array}{l}89,2 \% \text { das meninas e } \\
90,3 \% \text { dos meninos } \\
\text { souberam definir } \\
\text { adequadamente o } \\
\text { conceito de DST. }\end{array}$ \\
\hline $\begin{array}{l}\text { 8. Campos et } \\
\text { al., (2018) } \\
\text { BVS }\end{array}$ & $\begin{array}{l}\text { Diálogos com } \\
\text { adolescentes } \\
\text { sobre direitos } \\
\text { sexuais na escola } \\
\text { pública: } \\
\text { intervenções } \\
\text { educativas } \\
\text { emancipatórias! }\end{array}$ & $\begin{array}{l}29 \text { adolescentes de } 15 \text { a } \\
18 \text { anos, alunos do } \\
\text { ensino médio de escola } \\
\text { pública. }\end{array}$ & $\begin{array}{l}\text { Compreender } \\
\text { significados e } \\
\text { saberes de } \\
\text { adolescentes sobre } \\
\text { direitos sexuais para } \\
\text { subsidiar } \\
\text { intervenções } \\
\text { educativas } \\
\text { emancipatórias nas } \\
\text { escolas. }\end{array}$ & $\begin{array}{l}\text { Há } \\
\text { falhas e omissões entre } \\
\text { o que se estabelece nas } \\
\text { leis e sua efetivação no } \\
\text { cotidiano dos } \\
\text { adolescentes, com } \\
\text { violações } \\
\text { aos seus direitos sexuais, } \\
\text { tais como poucas } \\
\text { informações qualificadas } \\
\text { sobre sexualidade, a } \\
\text { falta da educação em } \\
\text { sexualidade nas escolas } \\
\text { para todos os alunos. }\end{array}$ \\
\hline $\begin{array}{l}\text { 9. Savegnago } \\
\text { \& Arpini } \\
(2018) \\
\text { DOAJ }\end{array}$ & $\begin{array}{l}\text { Olhares de mães } \\
\text { de grupos } \\
\text { populares sobre a } \\
\text { educação sexual } \\
\text { de filhos } \\
\text { adolescentes. }\end{array}$ & 17 mães de adolescentes. & $\begin{array}{l}\text { Conhecer os olhares } \\
\text { de mães de grupos } \\
\text { populares a respeito } \\
\text { dos diálogos sobre } \\
\text { sexualidade com } \\
\text { seus filhos } \\
\text { adolescentes, } \\
\text { principalmente no } \\
\text { que se refere aos } \\
\text { desafios } \\
\text { enfrentados e aos } \\
\text { papéis } \\
\text { atribuídos à escola e } \\
\text { aos serviços de } \\
\text { saúde pública. }\end{array}$ & $\begin{array}{l}\text { Os resultados } \\
\text { evidenciaram } \\
\text { que as mães } \\
\text { participantes têm } \\
\text { apresentado } \\
\text { dificuldades para } \\
\text { dialogar sobre } \\
\text { sexualidade com os } \\
\text { filhos. }\end{array}$ \\
\hline $\begin{array}{l}\text { 10. Barbosa et } \\
\text { al., (2019) } \\
\text { BVS }\end{array}$ & $\begin{array}{l}\text { Percepção dos } \\
\text { adolescentes } \\
\text { sobre sexualidade } \\
\text { e saúde } \\
\text { reprodutiva: a } \\
\text { escola como } \\
\text { espaço de } \\
\text { educação sexual. }\end{array}$ & $\begin{array}{l}\text { Adolescentes escolares } \\
\text { do } 6^{\circ} \text { ao } 9^{\circ} \text { ano de } \\
\text { educação básica. }\end{array}$ & $\begin{array}{l}\text { Analisar a percepção } \\
\text { e o conhecimento } \\
\text { dos adolescentes } \\
\text { sobre } \\
\text { Infecções } \\
\text { Sexualmente } \\
\text { Transmissíveis } \\
\text { (DST's), gravidez e } \\
\text { formas de } \\
\text { prevenção através } \\
\text { da contracepção } \\
\text { através de métodos } \\
\text { contraceptivos }\end{array}$ & $\begin{array}{l}\text { Observa-se que os } \\
\text { adolescentes } \\
\text { pesquisados são } \\
\text { vulneráveis, } \\
\text { uma vez que a pesquisa } \\
\text { revelou que a maioria } \\
\text { dos adolescentes não } \\
\text { conhece o assunto ou } \\
\text { não tem as informações } \\
\text { necessárias } \\
\text { para se protegerem. }\end{array}$ \\
\hline
\end{tabular}


Tabela 1. Síntese dos principais artigos apresentados na revisão sistemática (conclusão)

\begin{tabular}{|c|c|c|c|c|}
\hline $\begin{array}{c}\text { Autores/Ano } \\
\text { bases de } \\
\text { dados }\end{array}$ & $\begin{array}{c}\text { Título } \\
\text { da publicação }\end{array}$ & Participantes & Objetivos & Resultados \\
\hline $\begin{array}{l}\text { 11. Fereira et } \\
\text { al., (2019) } \\
\text { BVS }\end{array}$ & $\begin{array}{l}\text { Sexualidade na } \\
\text { Percepção de } \\
\text { Adolescentes } \\
\text { Estudantes da } \\
\text { Rede Pública de } \\
\text { Ensino: } \\
\text { Contribuição para } \\
\text { o Cuidado. }\end{array}$ & $\begin{array}{l}46 \text { estudantes que } \\
\text { atenderam aos seguintes } \\
\text { critérios de inclusão: } \\
\text { estar na faixa etária de } \\
13 \text { a } 18 \text { anos de idade; } \\
\text { estar } \\
\text { matriculado } \\
\text { regularmente na rede } \\
\text { estadual de ensino. }\end{array}$ & $\begin{array}{l}\text { Discutir a percepção } \\
\text { de adolescentes } \\
\text { acerca da } \\
\text { sexualidade } \\
\text { no espaço escolar. }\end{array}$ & $\begin{array}{l}\text { Obteve-se a formação } \\
\text { da seguinte categoria: a } \\
\text { sexualidade no cotidiano } \\
\text { dos adolescentes - um } \\
\text { desafio para a educação } \\
\text { sexual e reprodutiva, em } \\
\text { que foi trabalhado estes } \\
\text { aspectos: a sexualidade } \\
\text { relacionada ao ato de } \\
\text { gerar filhos; o } \\
\text { desconhecimento } \\
\text { dos adolescentes acerca } \\
\text { da saúde sexual e } \\
\text { reprodutiva. }\end{array}$ \\
\hline $\begin{array}{l}\text { 12. Furlanetto } \\
\text { et al., (2019) } \\
\text { BVS }\end{array}$ & $\begin{array}{l}\text { Acesso e qualidade } \\
\text { da informação } \\
\text { recebida sobre } \\
\text { sexo e sexualidade } \\
\text { na perspectiva } \\
\text { adolescente. }\end{array}$ & $\begin{array}{l}253 \text { adolescentes } \\
\text { matriculados em duas } \\
\text { escolas municipais. }\end{array}$ & $\begin{array}{l}\text { Entender as fontes e } \\
\text { limites de acesso às } \\
\text { informações sobre } \\
\text { sexo e sexualidade }\end{array}$ & $\begin{array}{l}\text { Os dados sugerem uma } \\
\text { lacuna entre a } \\
\text { transmissão de } \\
\text { informações } \\
\text { sobre sexo e sexualidade } \\
\text { nos contextos } \\
\text { investigados e o } \\
\text { comportamento } \\
\text { preventivo dos } \\
\text { adolescentes. }\end{array}$ \\
\hline $\begin{array}{l}\text { 13.Grossman } \\
\text { et al., (2019) } \\
\text { BVS }\end{array}$ & $\begin{array}{l}\text { Perspectivas dos } \\
\text { pais sobre a } \\
\text { Sexualidade } \\
\text { Familiar } \\
\text { Comunicação do } \\
\text { ensino médio para } \\
\text { o ensino médio. }\end{array}$ & $\begin{array}{l}23 \text { pais. Os participantes } \\
\text { eram em grande parte } \\
\text { mães e eram de diversas } \\
\text { raças/étnicas e } \\
\text { educacionais. } \\
\text { origens. }\end{array}$ & $\begin{array}{l}\text { Avaliar a } \\
\text { continuidade e a } \\
\text { mudança nas } \\
\text { percepções dos pais } \\
\text { da comunicação } \\
\text { entre os } \\
\text { adolescentes e os } \\
\text { pais. }\end{array}$ & $\begin{array}{l}\text { Muitos pais adaptaram } \\
\text { suas conversas } \\
\text { com seus adolescentes } \\
\text { sobre sexo e } \\
\text { relacionamentos à } \\
\text { medida que os } \\
\text { adolescentes se } \\
\text { desenvolviam. }\end{array}$ \\
\hline $\begin{array}{l}\text { 14.Matos } \\
(2020) \\
\text { SCIELO }\end{array}$ & $\begin{array}{l}\text { Estratégia } \\
\text { educacional sobre } \\
\text { as consequências } \\
\text { de relações } \\
\text { sexuais precoces } \\
\text { em adolescentes } \\
\text { a comunidade "El } \\
\text { Carmen". }\end{array}$ & $\begin{array}{l}100 \text { adolescentes } \\
\text { registrados na } \\
\text { comunidade de El } \\
\text { Carmen e na amostra de } \\
30 \text { adolescentes. }\end{array}$ & $\begin{array}{l}\text { Projetar um } \\
\text { programa de } \\
\text { intervenção } \\
\text { educacional sobre } \\
\text { as consequências de } \\
\text { uma } \\
\text { de relações sexuais } \\
\text { precoces no periodo } \\
2017-2018 .\end{array}$ & $\begin{array}{l}66,6 \% \text { dos adolescentes } \\
\text { foram encontrados com } \\
\text { um déficit de } \\
\text { conhecimento. } \\
\text { Após a intervenção } \\
\text { educacional, } 89,99 \% \text { dos } \\
\text { adolescentes } \\
\text { responderam } \\
\text { corretamente. }\end{array}$ \\
\hline
\end{tabular}

Legenda: Artigos apresentados na revisão sistemática.

Fonte: Os autores (2021). 
Síntese dos principais artigos apresentados na revisão sistemática

Figura 1. Apresenta o fluxograma de seleção dos materiais, a partir dos critérios de inclusão e exclusão

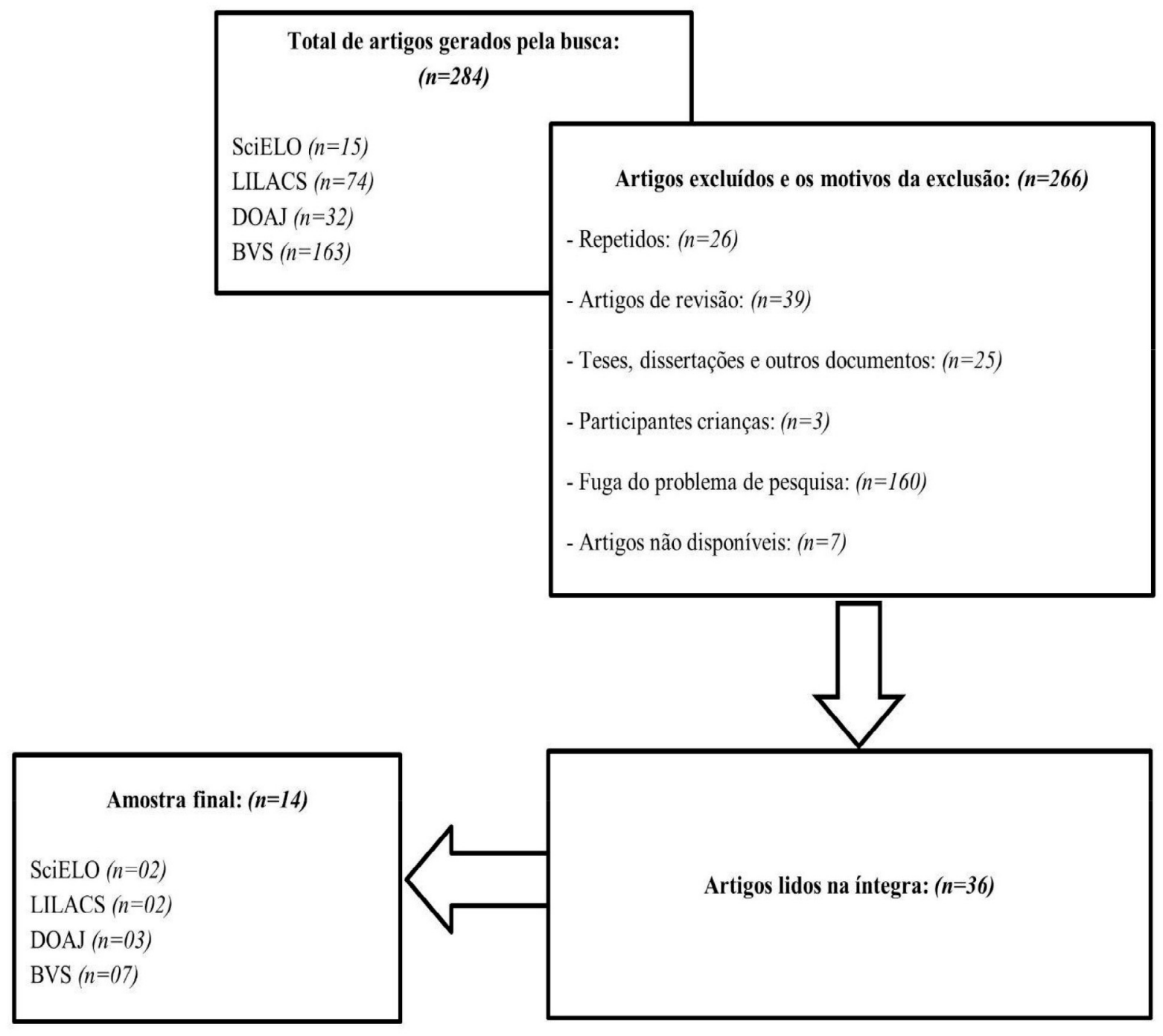

Legenda: fluxograma de seleção dos materiais.

Fonte: Os autores (2021). 
Para chegar a esses resultados e responder ao objetivo do estudo, fez-se uma análise dos artigos selecionados, buscando compreender os contextos que falam sobre educação sexual e chegou-se a uma categoria "Educação sexual em diferentes contextos". Os resultados apontaram que $86,6 \%$ (13) dos adolescentes e pais relatam que o conhecimento sobre educação sexual dos adolescentes ocorre no contexto familiar, mesmo sendo informações genéricas e superficiais. Cerca de $66,6 \%$ (10) dos adolescentes e/ou pais relatam que a escola retrata em algum momento o assunto. Já a tecnologia é um meio de acesso citado de $40 \%$ (6) dos participantes da pesquisa, seguido da troca de informações com amigos $40 \%$ (6) e da busca por informações com profissionais da saúde $26,6 \%$ (4). Isso pode ser verificado visualmente no gráfico 1:

Gráfico 1. Fluxograma de seleção dos artigos

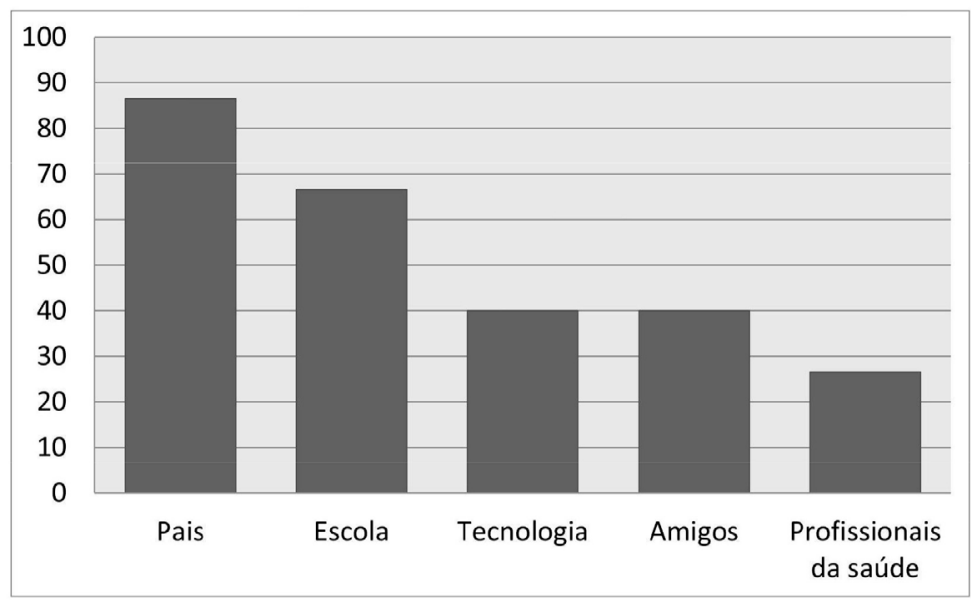

Legenda: Seleção dos artigos. Fonte: Os autores (2021).

Percebeu-se que $100 \%$ dos documentos retratam as informações sobre o tema como insuficientes e precárias, principalmente nos contextos familiar e escolar. No que se refere aos participantes, $71,4 \%$ (6) eram adolescentes e $28,5 \%$ (4) pais (pai e mãe), sendo que dentro desse panorama $21,4 \%$ (3) das entrevistadas eram as mães e o restante, $7,1 \%$ (1) eram pais. Além disso, a maioria das pesquisas foram realizadas no Brasil sendo 42,8\% (6) correspondem a Região Sul, todas do estado do Rio Grande do Sul, 14,2\% (2) Região Nordeste, 7,14\% (1) Região Norte, 7,14\% (1) Região Sudeste, 7,14\% (1) Região Centro. E 21,4\% (3) são estudos relacionados a outros países.

O caminho metodológico para chegar a esses resultados foi identificar nos artigos selecionados a região dos estudos, se eram brasileiros ou internacionais. Caso fossem brasileiros, foram divididos por regiões, e se fossem internacionais eram agrupados em um novo conjunto denominado "outros países". Tudo isso pode ser bem visualizado no gráfico 2: 
Gráfico 2. Pesquisas acerca do tema sexualidade

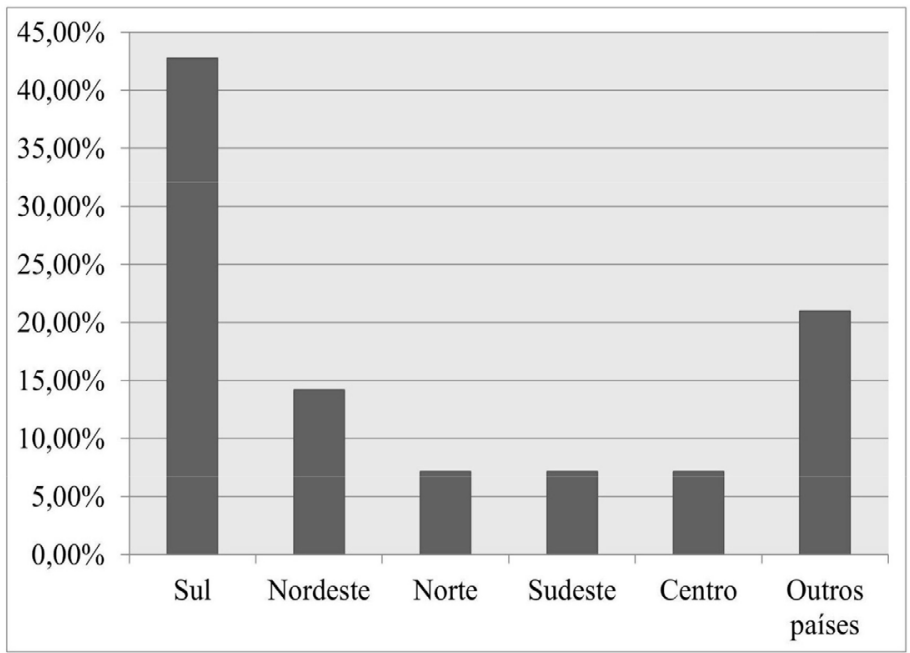

Legenda: Pesquisas acerca do tema sexualidade. Fonte: Os autores. (2021).

Quanto ao ano de publicação de estudo, 21,4\% (3) dos estudos referem-se ao ano de 2016, 28,6\% (4) dizem respeito a $2017,14,2 \%$ (2) a 2018, 28,6\% (4) a 2019 e 7,14\% (1) foi publicado em 2020 . Outro ponto importante a dar destaque é que $64,2 \%$ (6) dessas pesquisas foram realizadas pela área da enfermagem e 35,7\% (5) dos artigos encontrados foram pesquisas realizadas pela psicologia. A média de idade dos adolescentes desta pesquisa foi de 16,1 e a média da idade dos pais foi de 42,2.

No que se refere ao contexto familiar, à maioria dos estudos encontrados ressalta que as informações sobre educação sexual são insuficientes (Almeida et al., 2017; Barbosa et al., 2019; Bezerra et al., 2016; Campos et al., 2018; Ferreira et al., 2019; Furlanetto et al., 2018; Freire et al., 2017; Genz et al., 2017; Grossman et al., 2019; Matos, 2020; Sevilla et al., 2016; Rolim et al., 2016; Savegnago \& Arpini, 2018; Sevilla et al., 2016). E isso acontece devido a dois motivos principais, filhos que não se sentem confortáveis de falar sobre sexo e sexualidade por vergonha dos pais (Bezerra et al., 2016; Campos et al., 2018; Freire et al., 2017; Genz et al., 2017; Rolim et al., 2016; Sevilla et al., 2016) e pais que se sentem despreparados para falar sobre educação sexual com os adolescentes (Savegnago \& Arpini, 2018) ou desconfortáveis em algumas situações (Grossman et al., 2019).

Os principais temas retratados sobre sexo na família são infecções sexualmente transmissíveis e gravidez na adolescência (Bezerra et al., 2016; Campos et al., 2018; Savegnago \& Arpini, 2016 ). Sendo que as meninas buscam muito mais as mães, enquanto os meninos buscam mais a figura do pai para sanar suas dúvidas (Genz et al., 2017). No que se refere a importância de discutir sobre a temática como uma maneira de prevenção e promoção à saúde, a maioria dos pais e adolescentes considera a discussão como fundamental (Rolim et al., 2016; Grossman et al., 2019; Savegnago \& Arpini, 2016) embora existam lacunas ou insuficiência na transmissão de informação.

No que se refere ao momento para começar a falar a respeito da sexualidade, os estudos apontam resultados diferentes. Algumas famílias ressaltam serem favoráveis ao adiamento da iniciação da vida sexual até o filho(a) terminar a faculdade, conseguir um bom emprego ou simplesmente pela religião ou crença familiar, evitando assim falar sobre o assunto (Grossman et al., 2019). Outras famílias sentem a necessidade de discutir sobre sexo apenas quando percebem que o filho(a) assumiu um namoro (Grossman et al., 2019; Sevilla et al., 2016). Para alguns adolescentes, as famílias acham que ainda não é o momento para falar sobre sexo, mesmo os filhos questionando alguns pontos sobre o assunto (Freire et al., 2017). Contudo, alguns pais orientam sobre práticas sexuais seguras desde muito cedo, porque além de desejarem que seus adolescentes sigam os estudos, e estejam protegidos de riscos futuros, não desejam ser pegos de surpresa com perguntas sobre sexo e sexualidade (Grossman et al., 2019). 
No que diz respeito ao contexto escolar, a maior parte dos achados considera a escola como um ambiente propício para discutir sobre o ensino da educação sexual e sexualidade (Almeida et al., 2017; Barbosa et al., 2019; Bezerra et al., 2016; Campos et al., 2018; Ferreira et al., 2019; Furlanetto et al., 2018; Freire et al., 2017; Grossman et al., 2019; Rolim et al., 2016). Entretanto, a discussão é insuficiente, visto que as informações são restritas e com poucas aulas sobre o tema (Almeida et al., 2017; Bezerra et al., 2016; Campos et al., 2018; Ferreira et al., 2019; Grossman et al., 2019; Rolim et al., 2016). Alguns dos aspectos apontados, que tornam as aulas cansativas, é que existem mitos, crenças e tabus que não são discutidos em aula (Savegnago \& Arpini, 2016), a linguagem adotada pelos professores é de difícil acesso (Almeida et al., 2017), e falta espaço para o diálogo e envolvimento dos alunos (reire et al., 2017).

Diante disso, a tecnologia e a troca de informações com os amigos próximos são meios que os adolescentes se sentem mais confortáveis em buscar informações (Bezerra et al., 2016; Genz et al., 2017; Rolim et al., 2016; Savegnago \& Arpini, 2016, 2018). Nessas duas categorias as informações podem ser trocadas através da televisão, e conteúdos disponibilizados na internet como vídeos (Furlanetto et al., 2018; Rolim et al., 2016; Savegnago \& Arpini, 2016). Em relação a isso, existe uma grande preocupação dos pais nas informações que são buscadas e obtidas pelos adolescentes (Savegnago et al., 2019).

Por último, tanto os pais quanto os adolescentes podem buscar orientações através do conhecimento de profissionais da saúde (Bezerra et al., 2016; Campos et al., 2018; Genz et al., 2017; Savegnago \& Arpini, 2016). Principalmente quando a família não sabe como conduzir uma discussão (Savegnago \& Arpini, 2018) ou quando os adolescentes se sentem constrangidos ou desconfortáveis em iniciar a conversa com os pais (Bezerra et al., 2016).

\section{Discussão}

Em linhas gerais, as orientações e informações sobre educação sexual são direitos previstos na legislação para os adolescentes, o que reflete na qualidade de vida desses jovens. Quando esses direitos são negados, ou mesmo insuficientes como apontam os resultados da pesquisa, os adolescentes podem construir saberes a partir de suas próprias vivências. A falta de informações pode levar a prática sexual desprotegida, sendo fundamental a abertura para o diálogo, principalmente no contexto familiar (Campos et al., 2018; Matos, 2020).

No caso das famílias que se sentem despreparadas em discutir sobre educação sexual com os filhos, as Equipes de Saúde da Família podem auxiliar em algumas dúvidas básicas (Campos et al., 2018). Destaca-se que os pais podem ter enfrentado as mesmas dificuldades de falar sobre o assunto na sua adolescência com seus pais, e podem ainda hoje não ter informações suficientes para auxiliar seus filhos (Costenaro et al., 2020). Assim, mesmo que os pais não se intimidem para falar sobre sexo e sexualidade a tarefa de discutir a temática com um adolescente pode ser difícil e árdua, além de provocar o afastamento temporário pode até prejudicar a relação (Wight \& Fullerton, 2013). O discurso familiar em relação a educação sexual deve ir muito além do sexo na adolescência, deve visar proteção, prevenção e promoção da saúde (Costenaro et al., 2020).

Pode haver lacunas na comunicação entre pais e fiIhos, pois os adultos podem querer impor alguns tópicos e não abrir espaços para o diálogo e a discussão de temas relacionados à sexualidade dos adolescentes (Sevilla et al., 2016). Desse modo, embora os adolescentes possuam alguns conhecimentos prévios sobre educação sexual e situações de riscos, ainda assim podem estar diante de vulnerabilidades 
em relação às doenças sexualmente transmissíveis e a gravidez indesejada (Bezerra et al., 2016). Neste sentido, fica evidente a importância do desenvolvimento de programas/oficinas de educação sexual e da Síndrome da Imunodeficiência Adquirida (AIDS) como uma forma preventiva nas escolas e nos municípios. No entanto, a maioria dos adolescentes desconhece esses meios de educação, o que torna necessário que os órgãos públicos tornem mais acessíveis esses programas nas escolas e nos serviços de saúde (Rolim et al., 2016).

Outro ponto a destacar, é que a escola, juntamente com a família, são fundamentais na elaboração sobre a temática. Para que o assunto seja atrativo ao público adolescente podem-se propor espaços de promoção da saúde sexual, os quais considerem os interesses e oportunizem a participação ativa dos participantes (Freire et al., 2017). Oficinas ou espaços de diálogo aberto são alternativas para tanto (Costenaro et al., 2020). Ademais, um dos fatores relacionados à breve discussão sobre o tema nas escolas é o fato da temática sexualidade estar presente exclusivamente no currículo da disciplina de ciências, limitando-se assim a debater o assunto em outros espaços (Vieira \& Matsukura, 2017).

Nesse sentido, a tecnologia pode facilitar o aprendizado individual e coletivo acerca da saúde sexual. Contudo, deve-se considerar que a adolescência se trata de uma fase do desenvolvimento que favorece a vulnerabilidade a riscos, e na qual costuma-se iniciar a vida sexual. Dessa forma, a limitação no acesso a informações em fontes mais seguras, como a família, a escola e os profissionais da saúde, pode estar relacionada a vergonha, as crenças pessoais ou até mesmo receio de os pais percebam o interesse pelo assunto (Aragão, 2016). Juntamente com a tecnologia encontra-se a troca de informações sobre educação sexual com amigos e colegas, o que pode ser preocupante se considerar que se pode não ter acesso a um conteúdo confiável sobre a temática (Almeida et al., 2017).

É perceptível na pesquisa que todos os contextos discutidos são complementares. Assim, a família, a escola e os profissionais da saúde podem atuar em conjunto na prevenção e promoção da educação e saúde sexual. A tecnologia pode ser usada como um recurso na busca de informações a serem discutidas nesses contextos, bem como as trocas de informações, curiosidades e dúvidas advindas de amigos e colegas. Quando a atuação é coletiva e a educação sexual inicia desde a infância, pode-se ter uma vida sexual mais satisfatória, saudável e responsável.

\section{Considerações finais}

Conclui-se, a partir da percepção de pais e filhos, que existem falhas na educação sexual transmitida aos adolescentes nos mais diversos contextos. No que se refere ao ambiente familiar, o principal entrave é o desconforto dos adolescentes em falar sobre sexo e sexualidade com os pais. Da mesma forma, os pais sentem-se despreparados ao tocar nesses assuntos. Já no contexto escolar a limitação do tempo para debate e diálogo é limitado apenas às disciplinas de ciências.

Neste panorama, devido à falta de espaço para o diálogo, outras formas de acesso às informações como os meios tecnológicos e a rede de amigos são encontradas. Esses ambientes proporcionam aos adolescentes autonomia e fácil acesso. No entanto, há uma preocupação por parte dos pais diante desses meios, pois, nem todas as informações encontradas ali são confiáveis e serão repassadas dentro do grupo de amigos acarretando conhecimentos equivocados. Além disso, no contexto da saúde identifica-se a pouca procura de orientação sexual tanto por adolescentes como pelos pais, recorrendo a esses somente em situações muito específicas.

Logo, a educação sexual para adolescentes e famílias carece de espaços visando uma melhora na qualidade de vida dos envolvidos. Assim, fica evidente que o trabalho em conjunto entre família, escola e profissionais da saúde pode proporcionar a promoção e a prevenção da saúde sexual na adolescência. Por fim, o estudo realizado encontrou algumas limitações no sentido da precariedade de artigos dentro da área da Psicologia. Destaca-se a importância de estudo na área supracitada e também de espaços de escuta ativa aos adolescentes sem preconceitos morais construídos socialmente para que possam expressar seus anseios e dúvidas advindas do desenvolvimento sobre sexo e sexualidade. Outra lacuna encontrada é a falta de estudos que versam sobre a percepção 
do tema "educação sexual" na família, já que o material encontrado discutia o lado dos pais e/ou cuidadores ou dos filhos. Sugere-se, que mais estudos sejam realizados no contexto familiar colocando em contraponto a forma com que os pais falam sobre o tema e a forma com que os adolescentes recebem essas informações.

\section{Contribuições dos autores}

Danzmann, P. S., Vestena, L. T., Silva, A. C. P. e Peixoto, M. J. R. participaram da concepção, delineamento, busca e análise estatística dos dados da pesquisa, interpretação dos resultados, redação do artigo científico.

\section{Conflitos de interesses}

Nenhum conflito financeiro, legal ou político envolvendo terceiros (governo, empresas e fundações privadas etc.) foi declarado para nenhum aspecto do trabalho submetido (incluindo, mas não se limitando a subvenções e financiamentos, participação em conselho consultivo, desenho de estudo, preparação de manuscrito, análise estatística, etc.).

\section{Referências}

Almeida, R. A. A. S., Corrêa, R. G. C. F., Rolim, I. L. T. P., Hora, J. M., Linard, A.G., Coutinho, N. P. S., \& Oliveira, P. S. (2017). Conhecimento de adolescentes relacionados às doenças sexualmente transmissíveis e gravidez. Revista Brasileira de Enfermagem, 70(5), 1033-1039. https://doi. org/10.1590/0034-7167-2016-0531

Aragão, J. M. N. (2016). Mídia social, Facebook, como tecnologia de educação em saúde sexual e reprodutiva de adolescentes escolares [tese, Universidade Federal do Ceará]. http:// repositorio.ufc.br/handle/riufc/21807

Arpini, D. M., \& Witt, C. S. (2015). As múltiplas formas de ser adolescente. In H. R. Campos, \& S. M. G. Sousa (Eds.). Emocore: Experiências grupais na constituição da adolescência. EDUFRN.

Barbosa, L. U., Machado, R. S., Pereira, J. C. N., Lima, A. G. T., Costa, S. S., \& Folmer, V. (2019). Percepção de adolescentes sobre sexualidade e saúde reprodutiva: A escola como espaço para a educação sexual. Cultura de los cuidados, 55, 25-54. https://doi.org/10.14198/cuid.2019.55.03
Bardin, L. (2016). Análise de conteúdo. Almedina.

Bezerra, E. P., Sousa, L. B., Cardoso, V. P., \& Alves, M. D. S. (2016). Percepção de adolescentes acerca da atividade de vida "exprimir sexualidade". Revista Cuidado é Fundamental Online, 9(2), 340-346. https://doi.org/10.9789/21755361.2017.v9i2.340-346

Bock, A. M. B. (2015). Perspectivas para a formação em psicologia. Psicologia Ensino \& Formação, 6(2), 114122. http://pepsic.bvsalud.org/scielo.php?script=sci_ arttext\&pid=S2177-20612015000200009

Campos, H. M., Paiva, C. G. A., Mourthé, I. C. A., Ferreira, Y. F., Assis, M. C. D., \& Fonseca, M. C. (2018). Diálogos com adolescentes sobre direitos sexuais na escola pública: Intervenções educativas emancipatórias! Pesquisas e Práticas Psicossociais, 13(3), e2437. http://seer.ufsj.edu.br/ index.php/revista ppp/article/view/3107

Costenaro, R. G. S., Jesus, M. I. A., Oliveira, P. P., Ross, M. R., Stankowski, S. S., \& Teixeira, D. A. (2020). Educação sexual com adolescentes promovendo saúde e socializando boas práticas sociais e familiares. Brazilian Journal of Development, 6(12), 100544-100560. https://doi. org/10.34117/bjdv6n12-519

Ferreira, E. A., Alves, V. H., Pereira, A. V., Rodrigues, D. P., Santos, M. V., \& Gabrielloni, M. C. (2019). Sexualidade na Percepção de Adolescentes Estudantes da Rede Pública de Ensino de Macapá. Revista de Pesquisa, 11(5), 12081212. https://pesquisa.bvsalud.org/portal/resource/pt/ biblio-1022310

Freire A. K. S., Melo M. C. P., Vieira M. P., Gomes I. M., Gomes J. L., Ribamar D. S., Coêlho V. S., Ferreira Neto A. J., Marques K. K., Silva G. E., Soares F. A. A., \& Costa M. M. (2017). Aspectos psicossociais da sexualidade na adolescência: Diálogos e aprendizagem na escola. Semina: Ciências Biológicas e da Saúde, 38(1), 3-14. https://doi. org/10.5433/1679-0367.2017v38n1p3

Furlanetto, M. F., Lauermann, F., Costa, C. B., \& Marin, A. H. (2018). Educação sexual em escolas brasileiras: Revisão sistemática da literatura. Cadernos de Pesquisa, 48(168), 550-571. https://doi.org/10.1590/198053145084

Furlanetto, M. F., Marin, A. H., \& Gonçalves, T. B. (2019). Acesso e qualidade da informação recebida sobre sexo e sexualidade na perspectiva adolescente. Estudos e pesquisas em Psicologia, 19(3), 644-664. https://doi. org/10.12957/epp.2019.46907 
Galvão, T. F., \& Pereira, G. P. (2014). Revisões sistemáticas da literatura, passos para sua elaboração. Epidemiologia e Serviços de Saúde, 23(1), 183-184. http://dx.doi. org/10.5123/S1679-49742014000100018

Galvão, T. F., Pansani, T. S. A., \& Harrad, D. (2015). Principais itens para relatar Revisões sistemáticas e Meta-análises: A recomendação PRISMA. Epidemiologia e Serviços de Saúde, 24(2), 335-342. https://doi.org/10.5123/S1679$\underline{49742015000200017}$

Gava, T., \& Villela, W. V. (2016). Educação em sexualidade: Desafios políticos e práticos para a escola. Sexualidad, Salud y Sociedad, 24, 157-171. https://doi. org/10.1590/1984-6487.sess.2016.24.07.a

Genz, N., Meincke, S. M. K., Carret, M. L. V., Corrêa, A. C. L., \& Alvez, C. N. (2017). Doenças sexualmente transmissíveis: Conhecimento e comportamento sexual dos adolescentes. Texto e Contexto: Enfermagem, 26(2), e5100015. https://doi. org/10.1590/0104-07072017005100015

Grossman, J. M., Jenkins, L. J., \& Richer, A, M. (2019). Parents' perspectives on family sexuality communication from Middle School to High School [As perspectivas dos pais sobre a comunicação da sexualidade familiar desde a escola secundária até ao ensino médio]. International Journal Environmental Research and Public Health, 15(1), 107. https://doi.org/10.3390/ijerph15010107

Matos, S. (2020). Estratégia de ensino sobre as consequências das relações sexuais precoces em adolescentes da comúnidade "O Carmen". Revista de Investigación en Salud, 3(8), 85-94. http://www.scielo.org.bo/scielo. php?pid=\$2664-32432020000200004\&_script=sci_arttext

Lei 8.069, de 13 de julho de 1990. (1990). Estatuto da Criança e do Adolescente. http://portal.mec.gov.br/seesp/arquivos/pdf/ lei8069_02.pdf

Organização Mundial de Saúde. (2009). Child and adolescent health and development[Saúde e desenvolvimento da criança e do adolescente]. Organização Mundial de Saúde; 2009. http:// www.who.int/child-adolescent-health/

Papalia, D. E., \& Feldman, R. D. (2013). Desenvolvimento humano. $\left(12^{\mathrm{a}}\right.$ ed.). Artmed.
Rolim, S. L., Bielenki, C. R. Z., Béria, J. U., Schermann, L. B., Santos, A. M. V., \& Arossi, G. A. (2016). Conhecimento e acesso aos programas de educação sexual e prevenção da Aids: Um estudo com adolescentes escolares. Aletheia, 49(2), 110-121. https://doi.org/10.29327/226091

Savegnago, S. D. O., \& Arpini, D. M. (2016). A abordagem do tema Sexualidade no contexto familiar: O ponto de vista de mães de adolescentes. Psicologia: Ciência e Profissão, 36(1), 130-144. https://doi.org/10.1590/1982-3703001252014

Savegnago, S. D. O., \& Arpini, D. M. (2018). Olhares de mães de grupos populares sobre a educação sexual de filhos adolescentes. Estudos e Pesquisa em Psicologia, 18(1), 8-29. https://doi.org/10.12957/epp.2018.38107

Seloilwe, E. S., Magowe, M. M., Dithole, K., \& Lawrence, J. S. (2015). Parent and youth communication patterns on HIV and AIDS, STIs and sexual matters: Opportunities and challenges [Padrões de comunicação dos pais e dos jovens sobre o VIH e a AIDS, as ISTs e as questões sexuais: Oportunidades e desafios]. Journal of Child and Adolescence Behavior, 3(203), 1000203. https://ubrisa. ub.bw/handle/10311/1825

Sevilla, T. S., Sanabria, J. P., Orcasita, L. D., \& Palma, D. M. (2016). Consistencies and Discrepancies in Communication Between Parents and Teenage Children About Sexuality [Consistências e discrepâncias na comunicação entre pais e filhos adolescentes sobre sexualidade]. Pandéia, 26(64), 139-147. https://doi.org/10.1590/1982-43272664201601

Vieira, P. M., \& Matsukura, T. S. (2017). Modelos de educação sexual na escola: Concepções e práticas de professores do ensino fundamental da rede pública. Revista Brasileira de Educação, 22(69), 453-474. https://doi.org/10.1590/S141324782017226923

Wight, D., \& Fullerton, D. (2013). A review of interventions with parents to promote the sexual health of their children [Uma revisão das intervenções com os pais para promover a saúde sexual de seus filhos]. Journal of Adolescent Health, 52(1), 4-27. https://doi.org/10.1016/j. jadohealth.2012.04.014 